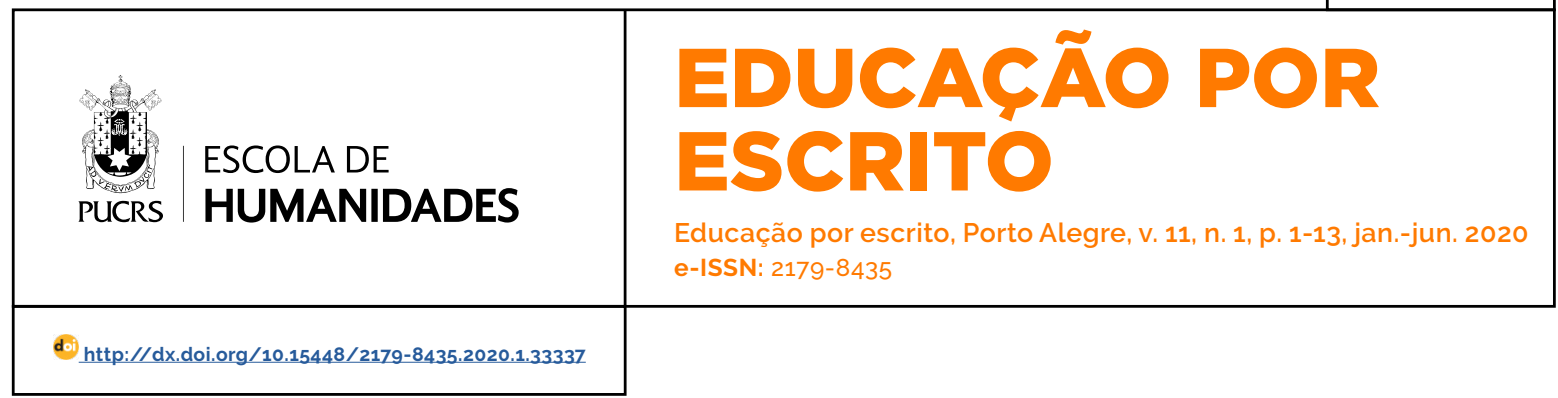

SEÇÃO ARTIGOS

\title{
O conceito de formação e a dinâmica do seu sentido no curso da história
}

The concept of formation and the dynamic of its meaning in the course of history

\section{Anthony Fábio Torres \\ Santana ${ }^{1}$ \\ orcid.org/0000-0001-9378-5879 \\ afabiotorres@hotmail.com}

\section{Dinamara Garcia \\ Feldens $^{2}$ \\ orcid.org/0000-0001-6471-3876 \\ dfeldens@hotmail.com}

\section{Lucas de Oliveira}

\section{Carvalho ${ }^{2}$}

orcid.org/0000-0002-0826-4567

lucas.historiando@gmail.com

Recebido em: 13 fev. 2019 Aprovado em: 8 jan. 2020 Publicado em: 27 jul. 2020
Resumo: Este artigo tem como objetivo apresentar o sentido atribuido ao conceito de formação ao longo do tempo, no curso da história. Ao pesquisar a formação, deparamo-nos, inevitavelmente, com a simplicidade de uma temática com a qual lidamos cotidianamente em nossas vidas, como também com o caráter complexo proveniente das caracteristicas singulares que a humanidade, no decorrer da sua trajetória, ajudou a constituir, em seus diferentes espaços e tempos, a respeito desse conceito. Vem desse movimento, a necessidade de tecermos um olhar cuidadoso para as nuances que estão compondo a ideia de formação, sobretudo, no campo da educação. Trata-se de um estudo de natureza qualitativa, que tem como aporte metodológico a pesquisa bibliográfica. Para composição do seu referencial teórico instrumentalizamo-nos com a leitura de: Rousseau, Kant, Gadamer, Jaeger e Hermann. Dessa forma, apresenta como resultado um resgate histórico do pensamento ocidental, evidenciando o sentido do que os gregos denominaram paideia, os latinos, humanitas, os alemães, bildung, e que hoje chamamos formação. Palavras-chaves: Formação. Pensamento Ocidental. Educação.

Abstract: This article aims to present the meaning attributed to the concept of formation over time, in the course of history. In researching formation, we are inevitably faced with the simplicity of a subject with which we deal daily in our lives, as well as with the complex nature derived from the unique characteristics that humanity, in the course of its trajectory, helped to constitute, in its different spaces and times, regarding this concept. From this movement comes the need to take a careful look at the nuances that are forming the idea of formation, especially in the field of education. This is a qualitative study, which has the methodological contribution to the bibliographic research. For composition of its theoretical framework we instrumentalize ourselves with the reading of: Rousseau, Kant, Gadamer, Jaeger and Hermann. In this way, it presents as a result a historical rescue of the western thought, evidencing the meaning of what the Greeks called paideia, the Latins, humanitas, the Germans, bildung and that today we call formation. Keywords: Formation. Occidental thought. Education.

\section{Introdução}

Ao pesquisar a formação, deparamo-nos, inevitavelmente, com a simplicidade de uma temática com a qual lidamos cotidianamente em nossas vidas, como também com o caráter complexo proveniente das características singulares que a humanidade, no decorrer da sua trajetória, ajudou a constituir, em seus diferentes espaços e tempos, a respeito desse conceito.

Possivelmente, um resgate histórico do pensamento ocidental nos ajude a esboçar esses movimentos e, então, consigamos perceber suas nuances e marcas mais expressivas, nos aproximando do que os gregos 
denominaram paideia; os latinos, humanitas; os alemães, bildung, e que hoje chamamos formação.

Antes, contudo, compete ressaltarmos que os gregos foram os primeiros representantes da cultura ocidental a se dedicarem, de maneira intencional, ao que designamos formação. No decorrer de quase um milênio, seus poetas, legisladores, retóricos, sofistas e filósofos, representantes de diversas escolas, pontuaram na história esse tema como fundamental ao aperfeiçoamento humano.

Sem desconsiderarmos a relevância dos poetas e dos sofistas gregos para a educação, é indispensável concebermos que, seguramente, o legado mais contundente à nossa formação foi deixado por seus filósofos. Para ilustrar esta afirmação, recorreremos, no encaminhamento desta escrita, às ideias de alguns dos seus mestres mais significativos, que ainda repercutem em nossas instituições formadoras e em diversos projetos formativos.

Nessa perspectiva, o presente texto pretende mostrar as alterações produzidas no sentido do conceito de formação ao longo do tempo. Para tanto, retoma dos gregos o aspecto metafísico e político da formação. Destaca na Idade Média a confluência entre o platonismo e o aristotelismo na composição da paideia cristã, enfatizando a sua incorporação e a sua remodelação pelos romanos como humanitas. E, por fim, apresenta o contexto da modernidade enquanto um território fértil para pensarmos a formação sobre a égide da razão, projetando dessa forma o horizonte da bildung.

\section{Os gregos e o sentido da paideia}

Naturais de Atenas, Sócrates e Platão foram contemporâneos de um contexto dividido entre a efervescência cultural e a crise política que, de forma contundente, afligia a sociedade ateniense. Nessa lógica, percebe-se com clareza que. sensiveis e mobilizados pelas questões sociais de seu tempo, ambos concentraram consideráveis esforços à compreensão e à posterior tentativa de resolução dos problemas estatais.

A percepção dos filósofos era que, somente por meio da tomada de consciência das pessoas em direção à possibilidade do conhecimento, do desenvolvimento das virtudes e da prática do bem, seria possivel assegurar condições para que a sociedade de Atenas pudesse superar a crise em que se encontrava envolvida. Evidentemente que, no interior dessa proposta, estavam contidas a concepção e a preparação de novos governos e governantes, além de uma possivel reestruturação mais justa da polis grega.

Se, por um lado, a preocupação com a formação dos cidadãos e dos futuros governantes, fundamentada na razão, continha em seu bojo a indicação de um porvir novamente promissor para Atenas; por outro, trazia uma crítica à forma de educação praticada pelos sofistas, professores encarregados da formação dos filhos da elite grega, a quem ensinavam com enfoque prático, sobretudo, a arte e o aperfeiçoamento da retórica, já que, em sua maioria, esses jovens eram encaminhados naturalmente à carreira política.

Como alternativa à crítica aos sofistas e ao tipo de educação que desenvolviam, Sócrates apresentava um dos componentes mais peculiares e instigantes do seu modo de fazer filosofia: a maiêutica. Com seu método provocativo, munido de questionamentos vigorosos, o filósofo tinha como propósito desarticular o conhecimento enciclopédico fundado em grande número no senso comum, ao mesmo tempo em que conduzia a pessoa a descobrir, por ela mesma, a essência das coisas e o sentido fundante da paideia, ou seja, a justiça.

Nesse deslocamento, Sócrates projeta ainda a filosofia em um novo estatuto ao alterar o curso de suas investigações antes voltadas para a observação da natureza como movimento viável de decifração do mundo e dos seus mistérios, passando a conceber, desde então, a ideia de o homem voltar-se para si mesmo. A sua hipótese era que, ao conectar-se com o seu interior, buscando compreender os anseios do seu próprio espírito, o homem alcançaria a desejada sabedoria, e se realizaria como pessoa ao contribuir por meio de uma conduta reta para o bem coletivo.

Discípulo de Sócrates, Platão também investe nos estudos acerca do entendimento da alma e da 
sistematização do cosmo moral. Nesse momento, as atenções, que antes estavam voltadas para a natureza física e social, vão sendo redirecionadas gradualmente para a figura humana (JAEGER, 1986). Se anteriormente o bem-estar do homem dependia quase que integralmente da organização das instâncias naturais e sociais, aos poucos, passa a se relacionar com a tranquilidade do seu espírito.

Não apenas a exploração do conhecimento, mas também a renovação moral do ser humano torna-se a chave da transformação política. Embora a virtude da qual nos fala Sócrates seja uma virtude interior, deve ser entendida como o elemento central de um novo projeto de formação do homem com manifestos interesses políticos. Mediante a educação, a alma se eleva ao nível dos bens permanentes da ordem racional e moral, constituindo-se, desse modo, no fundamento seguro do agir moral e político. O sentido integral da virtude representa agora a harmonia entre a existência moral do homem e a ordem natural do universo (GOERGEN, 2009, p. 28).

Nesse sentido, é possivel notar que, vislumbrando a construção de um estado justo, Platão evidencia a importância da ética como elemento essencial do processo formativo. Especialmente, como forma de realçar que a virtude verdadeira seria aquela capaz de relacionar o homem íntegro, de caráter forjado eticamente, com a disposição de transformar o meio social do qual faz parte. Dessa maneira, ao perceber e criticar a precariedade da formação dos governantes gregos, reivindicava a educação ética como tarefa e responsabilidade de toda sociedade, fundamentando o seu projeto educacional nos pilares da sabedoria e da justiça por compreender a relevância da renúncia dos interesses particulares ao projetar o bem social.

Nesse interim, a compreensão e o sentido atribuidos à paideia vão se distanciando do território demarcado pela aquisição de meras habilidades, paulatinamente passando a contemplar uma concepção integral de formação que, regida pelo exercício filosófico, vai balizando a constituição moral e política do homem da polis. Assim, Platão defendia que a reorganização estatal passaria antes, decisivamente, pela recomposição da virtude e da vida interior dos cidadãos e gestores, reservando aos filósofos a árdua tarefa de implementar um novo tempo norteado por uma educação ético-politica que visasse a verdade, a justiça e o bem como valores propícios a redefinição do ordenamento da sociedade.

A busca por um projeto formativo que contemplasse a formação integral do homem e a possibilidade de ajustes da ordem política grega acaba por fazer emergir duas concepções filosóficas: a filosofia do poder e a filosofia da formação. Em acordo com essa lógica, a primeira pretendia, por meio do uso da retórica, pôr em prática o seu desejo de dominação, conquistando o povo através do uso astucioso da linguagem em discursos rebuscados, que, muitas vezes, se mostravam vazios em termos de conteúdos qualificados. Com proposição oposta, a filosofia da formação objetivava o aperfeiçoamento humano, munindo-se para tamanha empreitada do uso da dialética como possibilidade para chegar ao conhecimento.

O que não se pode negar é que, ao levarmos em consideração ambos os projetos, somos colocados diante de dois tipos distintos de virtudes: uma que faz o manejo sagaz da oratória para exercer o poder, enquanto a outra concebe como substancial a busca da verdade fundamentada na atividade reflexiva, como possibilidade de constituição do cidadão virtuoso. Com isso, o futuro do homem grego estaria pautado pela autodeterminação moral constituida sobre a base do conhecimento da ideia de bem, concebendo na formação do cidadão o trajeto adequado de reconstrução da relação desgastada entre a política e a educação, ou em outras palavras entre a politeia e a paideia.

Completando a triade dos mais expressivos filósofos clássicos gregos, temos Aristóteles. A sua teoria em parte se alinha com o pensamento socrático-platônico. Ousamos dizer que este alinhamento reside demarcadamente no âmbito da valorização da educação, compreendida como um dos deveres do Estado elemento responsável por assegurar uma possivel condição estável ao homem em meio às diversas circunstâncias históricas.

Diferente de Platão, Aristóteles entendia 
que as ideias universais simbolizavam essências existentes nas coisas sensiveis, parte integrante daquilo que é o mundo. Com efeito, este posicionamento indicava o horizonte constituinte do seu modelo realista, que tem como cerne a investigação da realidade empírica. Provavelmente, o que Aristóteles não imaginaria era que, se opondo a Platão, idealista, acabaria por pontuar na história do pensamento ocidental uma dualidade que, de forma explícita, é facilmente percebida até os dias atuais, acima de tudo, por se constituir como cenário ao desenvolvimento do que entendemos na atualidade por formação.

Aristóteles pressupunha que, assim como a matéria alcançaria plenitude no processo de modificação de sua potência em ato, igualmente o ser humano, por ser dotado de potencialidades naturais, precisaria ser estimulado a desenvolvê-las no decorrer de sua existência. A efetivação dessa perspectiva se concretizaria por meio da educação, encarregada de conduzir o homem à adoção de hábitos virtuosos na projeção decorrente do domínio das suas paixões pelo uso da razão.

Nesse sentido, a felicidade do homem residiria na possibilidade da materialização da potência humana, ao orientar a sua vida por intermédio da ética e da moral. Adotando esses valores como norte para sua própria existência, o homem simultaneamente procurava controlar seus apetites e desejos, e obedecer às leis e às normas que regiam as condutas sociais com o objetivo de alcançar a sabedoria, compreendida, nesse contexto, como bem supremo.

Com isso, chegamos ao ponto em que se constituem os dois modelos formativos que podem ser considerados seminais para toda a história da educação do Ocidente, a saber: o idealismo platônico e o realismo aristotélico. Caracteriza-se, dessa forma, uma oposição que marca até hoje de forma expressiva o pensamento ocidental e, consequentemente, ilustra a paisagem em que se delineiam as diferentes formas por meio das quais concebemos a formação.
Da incorporação do ideal de paideia e a sua remodelação como humanitas

Ao avançarmos nessa história, torna-se possivel compreendermos que, por conta do destaque militar e político de que dispunha o Império Romano, esse acabou se envolvendo em diversos conflitos e, por conseguinte, se aproximando de outros povos e culturas. O desencadeamento desse processo acarretou sensiveis alterações em sua estrutura social, modificando também as suas diretrizes culturais e educativas. Talvez, o marco dessas transformações tenha sido o triunfo sobre a Grécia e a consequente racionalização e helenização ${ }^{3}$ da sua cultura.

É importante ressaltarmos que, até então, Roma possuía modelos políticos, culturais e econômicos tradicionalistas, fundamentados na agricultura e diferente dos gregos. Com efeito, seu horizonte educacional estava voltado para o desejo de formar o cidadão vinculado à família, prático e conhecedor dos seus direitos. Planos que vão sendo modificados, especialmente, por conta do impacto ocasionado pela absorção da cultura grega.

\begin{abstract}
A incorporação da noção e ideal de paideia, de formação humana pela cultura, remodelada como humanitas sob a liderança intelectual de Cícero, Quintiliano, Varrão, Sêneca e Marco Aurélio, representou a articulação entre a tradição pedagógica grega intelectualizada e a tradição romana prática, favorecendo o surgimento de um novo patamar de conhecimento pedagógico refletido (GOERGEN, 2009, p. 34).
\end{abstract}

Paralelamente ao estabelecimento dessa nova ordem junto aos romanos, não se pode deixar de citar a representatividade da revolução causada pelo surgimento e disseminação do cristianismo. Esse acontecimento foi responsável, a partir do fim do império, pela implementação de acentuadas mudanças não apenas nas instituições do mundo antigo, como igualmente em sua mentalidade.

Emergem, como fruto desse significativo deslocamento, novas formas de representações de homem e sociedade, o que, por sua vez, evidenciou a compreensão de que essas imagens eram nitidamente demarcadas por principios religiosos 
atribuidos a Deus e propagados pelos ordenamentos da Igreja, fundamentação que acabou produzindo uma ampla renovação, inclusive, espiritual.

A estreita relação entre o helenismo e a cultura emergente derivada do cristianismo forjou o que se conhece como paideia cristã. Essa nascente referência formativa acenava à possibilidade da condução do homem à virtude, com o olhar atento ao caráter universalista da formação, personificado na condição contemplativa e valorativa do outro. Realçamos que a vigência dessa conjuntura não impossibilitou a existência de uma notável ligação entre a tradição clássica grega e os aspectos instituidores da nova paideia. Aliás, pode-se atribuir a esta fusão a decorrente projeção sobre todo o medievo dos elementos culturais gregos.

Ainda que seja importante mencionar o referente periodo como um tempo histórico caracterizado pelo choque e estranhamento entre diferentes tradições, de maneira geral, pode-se conceber e afirmar que o platonismo e o aristotelismo se credenciaram como os dois segmentos do pensamento que serviram de base teórica para a construção dessa nova proposta de formação.

É do interior desse contexto que surge Santo Agostinho, filósofo de atuação expressiva junto ao clero e dono de um reconhecido trabalho intelectual que tem atribuida a si a fundamentação dos ideais éticos, políticos e antropológicos da paideia cristã. Nesse sentido, destacamos que coube ao seu construto filosófico a desafiadora missão de dar sustentação racional às ideias advindas do cristianismo.

Compete lembrarmos que o panorama educacional vigente se encontrava intimamente ligado à influência da Igreja, que a essa altura se firmava como instituição mais poderosa do Ocidente. Em decorrência, o dogma passava a nortear as práticas educativas à medida que também se tornava doutrina. Esse encadeamento desvela a educação da época como uma ação equivalente à catequese, tendo as instituições de ensino o foco direcionado à formação dos integrantes do clero.

A educação era, desse modo, pautada na ideia de obediência e buscava conduzir o homem à salvação por intermédio do controle das suas paixões. O desejo humano aqui era concebido enquanto pecado e estava diretamente relacionado aos impulsos carnais, evidência primeira da necessidade de sobrepor os anseios da alma - expressão de Deus - aos do corpo.

Considerado dádiva divina e algo revelado, o conhecimento era compreendido, nesse momento, como imutável, portanto, sinônimo de verdade e certeza. É nessa conjuntura que, alinhando-se a Platão, Agostinho apresenta a sua doutrina por meio da qual expõe a ideia de que o professor nada ensinava aos seus alunos que já não se encontrasse no interior de suas consciências. Para o filósofo, o papel do mestre seria criar condições para que seus discipulos pudessem entrar em contato com a verdade emanada de Deus e existente em seu intimo, objetivando, dessa forma, alcançar a paz de espírito.

Ao seguirmos essa incursão, nos deparamos, em meados do século XIII, com significativas tensões provocadas pelo contato entre as tradições cristãs medievais e as expressões culturais que se constituíam no interior de uma nova ordem social que lentamente passava a vigorar. Esse periodo representou a transição, por exemplo, de uma sociedade exclusivamente agrária para uma configuração social que vislumbrava os seus modos de produção direcionados para as cidades, com vistas ao desenvolvimento e estabelecimento de atividades comerciais urbanas.

Com isso, a Igreja sente a necessidade de se abrir às novas disposições culturais, e, com o intuito de se aproximar daquela realidade nascente, cria estrategicamente as ordens religiosas mendicantes. Sendo assim, de um lado, fundada por São Francisco de Assis, têmse a ordem dos franciscanos e do outro os dominicanos ligados a São Domingos Gusmão.

Em meio a essa efervescência, no plano do pensamento, desponta com protagonismo a figura de São Tomás de Aquino, membro filiado ao ordenamento dominicano e referendado como um dos grandes nomes da filosofia escolástica4. 0 seu protagonismo reside, sobretudo, na formulação

4 A Escolástica é um método de aprendizagem, com origem nas escolas monásticas, que concilia a fé cristã com um sistema de pensar racional, especialmente o da filosofia grega. 
de um sistema filosófico que conciliou a fé cristã com a tradição aristotélica, ato considerado revolucionário para época, especialmente, por levar em consideração possibilidades distintas as já conhecidas e prestigiadas ideias de Santo Agostinho.

Com efeito, a ação do filósofo moderou o tom espiritualista exacerbado de Platão que persistia junto à tradição agostiniana, passando, nesse movimento, a reconhecer também a dimensão corporal como componente da natureza humana. No entanto, o seu desejo e abertura à racionalidade não conseguiram impedir que ficasse destinada à teologia o estabelecimento da verdade acerca do mundo e das coisas.

Ao se basear na clássica distinção de Aristóteles entre ato e potência, Tomás de Aquino concebeu a educação como um meio através do qual o homem conseguiria desenvolver suas potencialidades em ato. Por sua vez, essa concepção de educação se distanciava de qualquer compreensão mecânica de ensino, já que o seu entendimento era pautado na ideia de que o professor nada transmitia, ou seja, apenas oferecia condições para que o aluno pudesse, por ele mesmo, experimentar conscientemente os processos formativos suscitados em seu entorno no decorrer da vida.

Nessa medida, os estímulos do mestre acabavam por desencadear atualizações das potencialidades já existentes em seus discípulos. Cabendo destacar que só a Deus era atribuída a capacidade de ensinar e, consequentemente, iluminar a mente humana, ficando, dessa maneira, reservado ao professor tão-somente a ação de estimular o despertar da potência intrínseca aos seus alunos.

Apesar de serem sucintas as referências presentes na filosofia de Santo Agostinho e São Tomás de Aquino no que concerne à educação, em sua totalidade, as suas obras representam grandes tratados da paideia cristã. Esse indício se mostra à medida que vem à tona o interesse último desses escritos, a saber: a salvação do povo cristão. Tratase de um modelo de formação que se valeu dos arcabouços teóricos dos dois principais filósofos gregos, agregando-lhes a verdade dos livros sagrados e da doutrina da lgreja.

As disputas travadas entre as diferentes tradições filosóficas medievais contribuiram, de maneira essencial, para o surgimento de ideias inovadoras que séculos mais tarde passariam a reorientar as diretrizes do campo educacional e a própria concepção de formação. Pode-se dizer que ali foi dado o primeiro passo em direção à concretização de um processo caracterizado pela gradual abertura a novas experiências educativas, e pela rejeição dos métodos autoritários e tradicionalistas que, objetivando a submissão e a obediência dos alunos, acabavam por limitar o alcance dos seus olhares compreensivos.

O referido deslocamento trouxe consigo consideráveis anseios que podem ser apreciados no construto filosófico elaborado por Erasmo de Roterdã. Considerado porta-voz do humanismo, o filósofo desempenhou importante papel ao criticar o caráter ressentido e moralizante em que estava pautada a educação medieval, criando, assim, condições para a efetivação de uma necessária revolução pedagógica que se mostrou, desde a sua gênese, comprometida com as aspirações dos sujeitos envolvidos em seus processos.

A pauta desse ideal de formação contemplava uma proposta educacional mais humana e integral, fundamentada em uma matriz teórica que rechaçava os maçantes e moralistas manuais escolásticos, ao indicar, em perspectiva distinta, a sua substituição pelo retorno ao estudo dos clássicos. A opção por voltar a se debruçar sobre as ideias gestadas no passado manifestava a possibilidade da composição de uma nova consciência histórica, que trazia consigo a intenção do avanço, a valorização da vida e de suas experiências possiveis.

Com isso, foram-se delineando alguns movimentos de renovação acerca da compreensão da própria ideia de homem, que passou a ser conduzida pela luz da razão, esboçando, de tal maneira, olhares mais amplos em relação ao mundo e ao futuro, munidos pelo desejo do progresso. Livres dos condicionamentos medievais e das determinações teológicas, essas produções intelectuais começaram a dar "cara" e "corpo" a essa importante fase de transição histórica, ao mesmo tempo que anunciavam a aurora da modernidade 
com a construção de uma mentalidade científica que atingiria com Kepler, Galileu, Descartes, Newton e Bacon feitos extraordinários.

A modernidade é uma "consciência de época", constituida através de um amplo movimento histórico, enraizado no humanismo renascentista e tem no iluminismo sua formulação central. Trata-se de uma crença na possibilidade razão de enunciar verdades universais, de entender e dominar o mundo, superar o mito e as forças mágicas e emancipar o homem. Quando a energia religiosa, que até então justificava o agir humano, se esvanece, abre-se o espaço para uma reflexão secularizada, uma ordem fundada na razão. O século XVIII foi particularmente rico em reformas sociais e utopias, inspiradas na crença da razão, trazendo muitos sonhos e uma forte expectativa de progresso. Esse otimismo não se manteve no século $X X$, porque a razão mostrou sua face opressiva. No desdobramento do movimento iluminista, diferentes projetos filosóficos, culturais e artísticos se debateram entre racionalização e contra-racionalização. Esse movimento já se reconhece em Baudelaire que, em meados do século XIX, renova a oposição da estética contra a moral e a ciência, e em Nietzsche que, no século XIX, propaga a substituição do cientista pelo artista, uma vez que a arte é a expressão mais adequada à vida. O século XX, com a proclamação das vanguardas estéticas, será o momento da afirmação dos valores revolucionários da emancipação individual e o pensamento filosófico, através da crítica de Adorno, Horkheimer, Heidegger, Foucault, entre outros, denuncia os aspectos restritivos da razão. Num tal contexto, a oposição entre o racional e o sensivel é profundamente questionada (HERMANN, 2010, p. 63).

\section{A chegada da modernidade: um novo contexto para pensar a formação}

O despertar da modernidade apresentou, como uma das suas expressões mais nítidas, as ideias de Jean-Jacques Rousseau, possivelmente o mais conhecido dentre os autores que fizeram parte do lluminismo ${ }^{5}$, movimento intelectual que inspirou a Revolução Francesa ${ }^{6}$. Atento às questões sociais e políticas do seu tempo, o filósofo suiço acreditava que a liberdade era um valor indispensável ao homem e, de maneira arrojada, apresentou uma concepção de educação transformadora para os moldes da época, apostando na visão naturalista do mundo em oposição ao trato racionalista para com as crianças.

A sugestão rousseauneana presente em sua clássica obra Emílio, publicada em 1762, firmou-se como um dos modelos de formação que permearam o século XVIII. O livro trazia um acentuado tom de oposição ao elitismo, forte marca daquele período, e criticava a escola tradicional de matriz cristã, que fazia o uso da pedagogia jesuítica, apoiada na rigidez, na catequese e na memorização como forma de transmitir conhecimentos, tratando os alunos como miniaturas de adultos.

Não só por isso, mas também por conceber uma formação voltada para o conhecimento empírico, compreendendo o corpo e a natureza como elementos importantes desse processo, é que essa obra do Rousseau é considerada revolucionária no que se refere à moderna pedagogia, estendendo-se, através do tempo, a sua influência pode ser encontrada no horizonte dos postulados da Escola Nova7.

Mas como educar o homem de forma natural? Essa foi uma das questões sobre as quais se debruçou o autor quando da escrita do seu Emílio. Dentro do que foi e representou para a história do imaginário iluminista, Rousseau se empenhou em criar uma proposta de educação reformadora que pudesse possibilitar sensiveis alterações sociais e políticas. Desse modo, ressignificou a infância, passando a compreendê-la como um momento particular da vida humana que se estende até por volta dos 12 anos, tempo em que começam a surgir os desvios, justificando, portanto, a necessidade de a primeira educação ser negativa. Ou seja, em suas ações durante essa fase, o mestre não precisaria ensinar novos saberes ao seu discípulo, ao contrário, apenas manter e fortalecer as condições morais inerentes ao mesmo.

5 "O termo iluminismo apresenta muitos equivalentes em línguas neolatinas, tais como "ilustração", "filosofia de luzes". Na filosofia alemã, encontra-se o termo "Aufklärung", traduzido como esclarecimento, que revela um processo social, político e histórico mais amplo que um movimento filosófico específico" (PRESTES, 1996, p. 16)

6 Para saber mais sobre o contexto, acontecimento e desdobramentos da Revolução Francesa, sugerimos a leitura do trabalho dos autores Mello e Donato, intitulado: "O pensamento iluminista e o desencantamento do mundo: Modernidade e a Revolução Francesa como marco paradigmático". A referência completa deste escrito segue junto às nossas referências.

7 "O escolanovismo surgiu em fins do século XIX, na Europa e nos Estados Unidos. Este movimento opunha-se às práticas pedagógicas tidas como tradicionais, visando uma educação que pudesse integrar o indivíduo na sociedade e, ao mesmo tempo, ampliar o acesso de todos à escola" (GALLO, 2001, p. 2) 
A educação primeira deve, portanto, ser puramente negativa. Ela consiste não em ensinar a virtude ou a verdade, mas em preservar o coração do vício e o espírito do erro. Se pudésseis conduzir vosso aluno são e robusto até a idade de doze anos, sem que ele soubesse distinguir sua mão direita de sua mão esquerda, logo às vossas primeiras lições os olhos de seu entendimento se abririam para a razão. Sem preconceitos, sem hábitos, nada teria ele em si que pudesse contrariar o resultado de vossos cuidados. Logo ele se tornaria, em vossas mãos, o mais sensato dos homens; e começando por nada fazer, terieis feito um prodígio de educação (ROUSSEAU, 1995, p. 80).

De acordo com o autor, durante a infância, o ideal seria que houvesse o mínimo de interferência possivel por parte do professor em relação à vida da criança. Talvez, o seu papel consistisse tão somente em proporcionar estímulos aos sentidos do aluno, na perspectiva de auxiliá-lo a descobrir o mundo e viver experiências.

Portanto, as atividades, segundo a proposição de Rousseau, deveriam ser dirigidas de acordo com o interesse da criança, conduzindo a educação mediante dificuldades progressivas, lúdicas e interativas que, posteriormente, evoluiriam de forma natural dos sentidos ao espírito. Nessa perspectiva, o objetivo seria estimular o conhecimento do mundo através do uso das faculdades sensiveis e da imaginação, ao sugerir uma formação cautelosa através do sentir e paulatinamente do pensar. Isso ocorreria sem, no entanto, sobrepor entre o mundo e o aluno qualquer signo, para que ele tivesse, desde cedo, contato com a realidade, pautando no seu horizonte a possibilidade, sempre plausivel, do acontecimento da experiência.

Nessa lógica, no decorrer da infância, não poderiam ser apresentadas às crianças ideias complexas nem abstratas. O aprendizado suscitado nesse periodo deveria, pois, se resguardar ao aprimoramento dos sentidos, compreendendo que "o único hábito que se deve deixar a criança adquirir é o de não contrair nenhum" (ROUSSEAU, 1995, p. 43).

Pensando com os subsídios indicados por Rousseau, logo chegamos a outro questionamento: como formar o homem naturalmente, conservando a sua liberdade e virtudes? Já nas primeiras palavras do Emilio, nos deparamos com a contundente ideia: "tudo é certo em saindo das mãos do autor das coisas, tudo degenera nas mãos do homem" (ROUSSEAU, 1995, p. 1). Na perspectiva rousseauneana, o individuo nasce bom, mas a sociedade, por meio das suas instituições, o corrompe, especialmente manipulando a sua mente e conduzindo a sua forma de pensar sobre o que vive e experimenta. Provavelmente, uma pretensa resposta para a pergunta colocada anteriormente passe pela viabilidade do fortalecimento da educação na infância e na adolescência do sujeito, de tal maneira que este se constitua como um homem idealmente incorruptivel.

Não podemos esquecer que a proposição apresentada no Emílio se compromete com a formação de um sujeito autônomo frente às instituições sociais, conduzindo-o ao desenvolvimento da capacidade de elaborar o seu pensamento a partir da sua história, do seu crescimento e amadurecimento. Certamente durante a vida, o homem se encontrará imerso na contingência de algum projeto político, deparandose, então, com a probabilidade de ter que recorrer a um contrato social ${ }^{8}$, através do qual negociará posições, fará acordos, tendo, por isso, que produzir, de maneira consistente, o seu próprio argumento.

Possivelmente, hoje não consigamos tomar estritamente a recomendação de educação do Rousseau pautada na liberdade e na ação de deixar a criança viver, e, portanto, experimentar, se surpreender, estranhar-se frente ao mundo em suas possibilidades, para que então só depois possa pensar a respeito do vivido, acerca de quais relações empreendeu a fim de chegar a determinadas conclusões. Esse processo requer tempo e, principalmente, paciência, qualidades raras nos dias atuais. Assim, ainda que munidos de boas intenções, por vezes, "atropelamos" etapas na urgência da verificação precoce dos resultados.

Em outra tradição, por meio da qual se pode perceber a existência de algumas dicotomias na

8 O contrato social é abalizado em um acordo no qual os sujeitos, em condições isonômicas, aprovam o poder designado a uma autoridade na qual eles confiam, e que, portanto, deve protegê-los e garantir o bem-estar da vida em sociedade. 
gênese do projeto moderno, o filósofo alemão Immanuel Kant propunha a possibilidade do uso da razão como estratégia formativa. Assim, competiria ao homem buscar a liberdade necessária para a constituição da sua própria maneira de pensar, por intermédio do exercício racional de compreensão dos fenômenos apresentados pelo mundo; elaborando, portanto, juizos na probabilidade da construção de conhecimentos, como forma de viabilizar o alargamento do seu horizonte compreensivo para além do que se é ofertado nos domínios do senso comum.

De acordo com Kant (2004, p. 11): "o homem é a única criatura que precisa ser educada. Por educação entende-se o cuidado de sua infância (a conservação, o trato), a disciplina e a instrução com a formação". Para tanto, seria fundamental que, desde cedo, a criança fosse conduzida cuidadosamente, recebendo tal educação, obviamente, de outros homens já formados.

Nesse contexto, é expressivo considerarmos não apenas a importância do outro para o desenvolvimento da formação, como também as tradições elaboradas pelas gerações antecedentes, uma vez que o nosso ponto de partida, via de regra, se concentra no que já foi mensurado e construido. Comumente nos instrumentalizamos dos fenômenos anteriormente refletidos com o intuito de compor novas trilhas formativas, não obstante, esses subsídios tendem a contribuir de maneira significativa para a nossa constituição frente ao mundo e aos outros.

A educação é uma arte, cuja prática necessita ser aperfeiçoada por várias gerações. Cada geração, de posse dos conhecimentos das gerações precedentes, está sempre melhor aparelhada para exercer uma educação que desenvolva todas as disposições naturais na justa proporção e de conformidade com a finalidade daquelas, e, assim, guie toda a humana espécie a seu destino (KANT, 2004, p. 19).

Ao continuarmos, reiteramos que um dos principais objetivos da proposta kantiana consistia no desejo de condução da formação humana ao aperfeiçoamento do uso da razão, livrando, quando possivel, o sujeito de formas de compreensões estreitas, a partir do que the é provocado pela experiência de leitura do mundo por meio dos sentidos. Portanto, tal proposição indicava a possibilidade de saída do homem da menoridade, condição que, nas palavras do filósofo, se apresentava como: "a incapacidade de se servir de seu próprio entendimento sem a tutela de um outro" (KANT, 2014, p. 1).

Conforme indicava o autor, a condução prudente do sujeito desde a sua infância à elaboração racional das suas formas de entendimento acerca do mundo, de si mesmo e dos outros dentro das oportunidades nascidas em seus diferentes percursos de formação, o encaminharia naturalmente ao esclarecimento (aufklärung), pelo qual ele seria o único responsável.

Segundo Kant:

\begin{abstract}
A preguiça e a covardia são as causas pelas quais uma parte tão grande dos homens, libertos há muito pela natureza de toda tutela alheia (naturaliter majorennes), comprazem-se em permanecer por toda sua vida menores; e é por isso que é tão fácil a outros instituirem-se seus tutores. É tão cômodo ser menor. Se possuo um livro que possui entendimento por mim, um diretor espiritual que possui consciência em meu lugar, um médico que decida acerca de meu regime, etc., não preciso eu mesmo esforçar-me (2014, p.1).
\end{abstract}

Ao agir dessa maneira, o homem priva-se de conhecer, por ele mesmo, o mundo em suas possibilidades. Submetendo-se demasiadamente às estruturas dos pensamentos alheios, perde a oportunidade de perceber, e refletir acerca dos fenômenos suscitados em seu entorno. Por fixar e reduzir o conhecimento apenas ao que os outros podem mensurar, acaba revelando a falta de comprometimento para consigo.

Para Kant, o sujeito deveria atribuir a si mesmo a condição de menoridade, porquanto ela resulta da união de aspectos como falta de coragem e apatia, e não da insuficiência da sua capacidade racional. Por se comportar desse modo, o homem acaba, consequentemente, por delegar de forma acomodada e, em alguns casos, irresponsável a tutela da sua formação a tutores despreparados, esquecendo que é do próprio entendimento que deve se servir, caso tenha em seu horizonte o desejo de atravessar a fronteira do esclarecimento. 
É inevitável reconhecer que, como poucos, Kant soube expressar com clareza o ideal educativo da ilustração, especialmente, ao apresentar a confiança no conhecimento formulado por meio da razão. Nesse ínterim, compete ainda mencionarmos que, no bojo do seu projeto de formação, era também perceptivel um tom acentuadamente moral que negava ao homem a possibilidade da prática do bem com o objetivo de alcançar o prazer.

Nesse sentido, o filósofo compreendia que um dos papéis reservados à educação seria o de conduzir o sujeito à elaboração do pensamento em termos universais. Em conformidade com essa lógica, encontramos no horizonte kantiano a perspectiva de que apenas as práticas fundamentadas em principios universalistas, capazes de serem tomadas como parâmetros para as ações coletivas, poderiam orientar o homem à convivência pacifica e feliz em sociedade.

Com efeito, este entendimento, além de nos projetar ao dilema histórico de pensar na justa proporção entre a composição de um programa de formação universal e o desejo individual por felicidade e realização, também demarca o território em que foi forjado um novo projeto formativo, por meio do qual o homem moderno assumiu o protagonismo e a responsabilidade da constituição de si e da criação de outro mundo possivel.

Portanto, se atualmente podemos falar em formação, antes, porém, é importante termos a percepção de que este conceito se encontra igualmente ligado à concepção da bildung e à sua representação no contexto da tradição humanista. É do interior deste intenso movimento de elaboração de uma nova proposta de mundo que brota a moderna referência formativa, segundo a qual o homem seria o único responsável por ser artífice de si mesmo.

\section{O horizonte projetivo da bildung ou da formação na contemporaneidade}

A partir do século XVIII, a compreensão da formação caracterizada pela bildung esteve intimamente relacionada aos conceitos de razão, emancipação, autonomia, maioridade e autodeterminação, expressando a capacidade humana de se projetar além da sua condição natural, ao exercer o livre direito de escolha que credencia o homem à autocriação. De acordo com este pensamento, o conceito clássico de bildung configura-se enquanto a ideia de o sujeito não ser determinado nem pela natureza, nem pelo fundamento teológico, mas pelas suas próprias ações (HERMANN, 2010).

Anteriormente, no entanto, durante a tradição mistica, de acordo com a qual o homem foi concebido segundo a imagem e semelhança de Deus, pode-se verificar certa cobrança para que o sujeito pudesse recompor esta alegoria em si, na trajetória complexa e desafiadora de se autoconstituir nos constantes embates consigo mesmo e com as referências que chegam por intermédio das relações intersubjetivas experimentadas com o mundo e o outro.

A história da filosofia mostra que a primeira definição ligada ao termo bildung expressava um sentido aproximado à formação natural do homem. Próximo porque bildung é uma palavra de dificil tradução. Ao prosseguir por entre os capítulos dessa trama, percebemos que, em seu desenvolvimento, o conceito de formação foi praticamente unido ao de cultura, passando a designar a condição de o sujeito aprimorar suas disposições naturais.

Contudo, existe uma diferença entre o significado de "cultura" e "formação", traço sutil percebido por Wilhelm von Humboldt. Debruçado sobre essa visão, Gadamer afirma que a "formação significa mais que cultura, ou seja, aperfeiçoamento de faculdades e talentos" (2008, p. 46). Ao tomar como referência as ideias humboldtianas, Hermann compreende ser preciso que o homem viva em uma multiplicidade de experiências, considerando a formação como "um trabalho de si mesmo, em uma abertura dialética entre a experiência no mundo e um projeto de mundo" (2010, p. 112-113). Desse modo, vivenciar tal pluralidade de acontecimentos seria indispensável para que o sujeito pudesse se formar de maneira ampla e, portanto, diversificada.

Um aspecto relevante a observarmos nesta incursão é a visão presente no horizonte projetivo 
da bildung, segundo a qual o homem precisa da formação para educar antes os seus instintos e, em última instância, para se tornar humano, rompendo, desta forma, o imediatismo e o impulso do agir irracional. A partir desse ponto de vista, Hegel chama a atenção para a natureza formal da formação: a universalidade. A esse respeito, Gadamer assevera que "a essência universal da formação humana é tornar-se um ser espiritual, no sentido universal" (2008, p. 47). Certamente, um exercício dificil de ser praticado, especialmente por requerer do sujeito o desprendimento do particular em favor da totalidade.

A bildung também foi retratada na literatura, por meio do bildungsroman ou romance de formação. Dentre os expoentes desse tipo de produção, pode-se citar o autor alemão Johan Wolfgang von Goethe que, em sua clássica obra Os anos de aprendizado de Wilhelm Meister, publicada originalmente em duas partes nos anos de 1795 e 1796, apresenta os embates vividos pela sua personagem principal no decorrer do seu processo formativo, explicitando, desse modo, seus limites ao se relacionar com o mundo e as distintas referências exteriores a si.

Nesses termos, não podemos falar sobre formação sem mencionar o conceito de alteridade. A formação acontece no contato entre o mundo interior e a contingência externa. O outro, de alguma maneira, vem nos mostrar o limiar da nossa existência com aquilo que emana e, dessa forma, reconhecemo-nos na medida em que a identidade se afirma na diferença.

O acesso clássico à alteridade advém do questionamento se sabemos quem é o outro. As dificuldades do sujeito moderno com essa temática, seja a pessoa do outrem ou das culturas, têm por base o modelo de autoformação da subjetividade que resulta numa dominação da diferença. A alteridade é um outro, do qual depende a própria identidade. O outro e o eu estão numa relação complexa em que se remetem reciprocamente. Assim, o outro não só está fora como dentro do indivíduo. E esse, sempre foi submetido a uma situação contraditória no pensamento filosófico, pois, na mesma medida em que foi reconhecido, sistematicamente foi também subtraido por meio de um violento mecanismo de abstração, em que, para afirmar aquilo que é universal, excluiu o estranho, a diferença, o irracional (HERMANN, 2010, p. 133-134).
A alteridade é, portanto, a capacidade do sujeito retirar-se do plano central da cena da vida e permitir a existência do outro, na relação simples e corajosa do diálogo possivel. Alteridade é a atitude radical de criar condições de possibilidade para que o outro possa fazer parte do nosso mundo, na trama da composição de uma linguagem comum. Cabe ressaltarmos que nem tudo está em nós, sendo assim, existe um universo inteiro de coisas possiveis que só conhecemos por intermédio da chegada do outro, no estranhamento provocado por esse indispensável e decisivo encontro.

Nesse interim, atento aos diferentes cenários e contornos históricos delineadores da bildung. Gadamer evidencia, como componente universal da formação, o "manter-se aberto para o diferente, para os outros pontos de vista mais universais" (2008, p. 53). Apesar disso, destacamos que as visões universalistas para as quais o homem em formação se mantém receptivo não se configuram como um padrão, algo estático e de validade definida, apresentando-se, em perspectiva distinta, apenas como probabilidades, nos fazendo compreender que o cerne da formação não é o alheamento, mas o retorno a si, que requisita antes a saída do seu território constituído.

Nesse sentido, a formação supera o mero desenvolvimento de recursos inerentes ao homem, ao indicar o aprimoramento do que foi aprendido em uma integração potente entre conhecimento e sujeito. Por isto, o aprendizado não se invalida, ou seja, é preservado nos levando à compreensão da formação enquanto um conceito genuinamente histórico. Portanto, "o resultado da formação não se produz na forma de uma finalidade técnica, mas nasce do processo interior de formulação e formação, permanecendo, assim, em constante evolução e aperfeiçoamento" (GADAMER, 2008, p. 46).

Ao longo da sua trajetória, especialmente durante a modernidade tardia, o conceito de formação começou a receber duras críticas por objetivar as ideias de unidade e totalidade que já não dispunham da mesma força de convencimento diante de um mundo plural em 
"orientações valorativas e não mais unificado na convergência de um ideal de humanidade" (HERMANN, 2010, p. 113). Com as consequentes e inevitáveis mudanças pelas quais passa a sociedade a partir desse momento, a formação vai paulatinamente esvaziando-se de seu sentido originário e, no bojo da globalização, passa a ser tomada como referência para designar a apreensão de instrumentalização técnica, contradizendo e enfraquecendo a gênese da sua concepção, principalmente por suprimir o seu tom crítico, componente imprescindivel para o sujeito comprometido com a sua autoconstrução.

\section{Considerações finais}

Assim, nos encaminhando para concluir, reiteramos a compreensão de que a formação é um processo contínuo na vida, constituído mediante o exercício paciente e corajoso do sujeito que se coloca o desafio do movimento na condição de romper com os elementos estabelecidos em sua subjetividade. Este percurso é construido por escolhas e consequências, realçando em seu acontecimento a necessidade do esforço e dedicação permanente.

Nessa medida, a formação é também um processo que deixa sempre ressonâncias de autores lidos, de pessoas com as quais compomos encontros, nos proporcionando a abertura para o reconhecimento da alteridade nessas relações, o que significa compreender o outro e o saber cultural. Possivelmente, essa seja a maior evidência de que a formação acontece na diferença, de maneira especial, porque o diferente não extingue possibilidades. Ousamos dizer que a formação é a mais arriscada aventura do homem e talvez a isto esteja fadada a sua existência, ou seja, à captura de novas referências e a posterior constituição de sentidos para si por meio do exercício intersubjetivo praticado.

A esse respeito, enfatizamos que a formação não é somente lugar de encontros, mas sobretudo, espaço de criação, de construção de realidades e das suas sucessivas desconstruções. É a atualização de discursos e práticas, caracterizando-se enquanto a procura por caminhos possiveis, onde o sujeito, munido de esperança, possa transitar (SANTANA, 2017).

Também por isso, a formação nos constitui a ponto de possibilitar o desenvolvimento de uma linguagem singular para expressar o que apreendemos do mundo. Dessa forma, construimo-nos experimentando situações plurais e pensando sobre os elementos e sujeitos com os quais nos relacionamos ao viver esses processos. Assim, formar-se é abrir mão do que estamos sendo, na iminência do risco de nos tornarmos novos sujeitos. É igualmente experimentar vários deslocamentos ao passo que já nos atamos a outros pontos referenciais. Por isso, é um processo que precisa ser fundado na seriedade e honestidade para consigo, uma vez que a formação não contempla todos os desejos nem contradições humanas.

Nessa perspectiva, não podemos conceber a formação apenas como um simples objetivo a ser seguido. Cabe-nos antes a proposição de questionamentos acerca desses processos: a quais tipos de formações estamos sendo submetidos? Quais experiências disponibilizamos aos outros? Esses aspectos precisam ser observados com parcimônia, principalmente em uma contemporaneidade ansiosa pela tão falada formação continuada. Esquecendo muitas vezes que, no fundo, formação não pode ser um objetivo, não pode ser desejada, a não ser na temática reflexiva do educador. Cabendo, portanto, a compreensão de que formação não é um ponto a que se chega, mas a abertura para que o sujeito descubra outros tantos caminhos possiveis, desde já constituidos como pontos de partida para a ampliação dos seus horizontes compreensivos.

\section{Referências}

GADAMER, Hans-Georg. Verdade e Método I: traços fundamentais de uma hermenêutica filosófica. Tradução de Flávio Paulo Meurer. 10. ed. Petrópolis, RJ: Vozes, 2008.

GALLO, Anita Adas. A noção de cidadania em Anísio Teixeira. In: Reunião anual da ANPED, 24., Caxambu, 2001. Anais [...]. Caxambu: Associação Nacional de Pós-graduação e Pesquisa em Educação. Caxambu: 2001. Disponivel em: http://www.anped.org.br/sites/ default/files/gto2_13.pdf. Acesso em: 12 jan. 2019. 
GOERGEN, Pedro. Formação ontem e hoje. In: CENCl, Ângelo Vitório; DALBOSCO, Cláudio Almir; MÜHL, Eldon Henrique (org.). Sobre filosofia e educação racionalidade, diversidade e formação pedagógica. Passo Fundo: Ed. Universidade de Passo Fundo, 2009.

GOETHE, Johan Wolfgang von. Os anos de aprendizado de Wilhelm Meister. São Paulo: Editora 34, 2006.

HERMANN. Nadja Mara Amilibia. Autocriação e horizonte comum: ensaios sobre educação ético-estética. Ijui: Ed. Unijuí, 2010

JAEGER, Werner. Paideia: a formação do homem grego. São Paulo: Martins Fontes, 1986.

KANT, Immanuel. Resposta à pergunta: o que é o Esclarecimento? Traduzido por Luiz Paulo Rouanet. Disponivel em: http://coral.ufsm.br/gpforma/2senafe/PDF/b47.pdf. Acesso em: 10 jan. 2019.

KANT, Immanuel. Sobre a Pedagogia. Tradução de Francisco Cock Fontanella. Piracicaba: Editora UNIMEP, 2004

MELLO, Denis S. de; DONATO, Manuella Riane. O pensamento iluminista e o desencantamento do mundo: Modernidade e a Revolução Francesa como marco paradigmático. Revista Crítica Histórica, Maceió, ano II, n. 4, jul./dez. 2011. Disponivel em: http:// www.revista.ufal.br/criticahistorica/attachments/ article/118/0\%20Pensamento\%20lluminista\%20 e\%200\%20Desencantamento\%20do\%20Mundo.pdf. Acesso em: 05 jan. 2019

PRESTES, Nadja Mara Hermann. Educação e racionalidade: conexões e possibilidades de uma razão comunicativa na escola. Porto Alegre: EDIPUCRS, 1996.

ROUSSEAU, Jean-Jacques. Emílio ou da educação. Tradução por Sérgio Milliet. 3. ed. Rio de Janeiro: Bertrand Brasil, 1995

SANTANA, Anthony Fábio Torres. Um olhar acerca do sentido da experiência na formação de professores. Tese (Doutorado) - PPGEDU, Porto Alegre, 2017.

\section{Anthony Fábio Torres Santana ${ }^{1}$}

Doutor em Educação pela Pontificia Universidade Católica do Rio Grande do Sul (PUCRS, Porto Alegre, RS, Brasil).

\section{Dinamara Garcia Feldens²}

Doutora em Educação pela UNISINOS. Professora da Universidade Federal de Sergipe (UFS, São Cristóvão, SE, Brasil).

\section{Lucas de Oliveira Carvalho²}

Mestrando pelo Programa de Pós-Graduação em Educação da Universidade Federal de Sergipe (UFS, São Cristóvão, SE, Brasil).

\section{Endereço para correspondência}

Anthony Fábio Torres Santana

Rua Rafael Pereira Rodrigues, 1631, bloco: "P", apto 404

Grageru, 49027015.

Aracaju, SE, Brasil

Dinamara Garcia Feldens

Rua Orlando Sobral dos Santos, 59

Aeroporto, 49038420

Aracaju, SE, Brasil

Lucas de Oliveira Carvalho

Rua Presbitero Aloísio Santos, 150, cjto. Augusto Franco

Farolândia, 49030650

Aracaju, SE, Brasil 